Ressources en ligne

\title{
L'éducation sur les sites des médias français
}

\section{Sophie Condat}

\section{CpenEdition}

\section{Journals}

Édition électronique

URL : http://journals.openedition.org/ries/1354

DOI : 10.4000/ries.1354

ISSN : 2261-4265

Éditeur

Centre international d'études pédagogiques

Édition imprimée

Date de publication : 1 avril 2005

Pagination : 12-13

ISSN : $1254-4590$

Référence électronique

Sophie Condat, "L'éducation sur les sites des médias français », Revue internationale d'éducation de Sèvres [En ligne], 38 | avril 2005, mis en ligne le 23 novembre 2011, consulté le 20 avril 2019. URL http://journals.openedition.org/ries/1354; DOI : 10.4000/ries.1354

Ce document a été généré automatiquement le 20 avril 2019

(c) Tous droits réservés 


\section{Ressources en ligne}

\section{L'éducation sur les sites des médias français}

\section{Sophie Condat}

1 L'école et l'éducation en général suscitent des débats au sein de la société et entrânent prises de position, échanges et polémiques. Les médias - télévision, radio, presse écrite papier et en ligne - s'en font l'écho et apportent des éclairages particuliers. Pour ce numéro, nous avons sélectionné des médias français qui proposent sur leur site une rubrique consacrée à l'éducation.

\section{Radio}

2 Tous les jeudis sur France Info à $07 \mathrm{~h} \mathrm{49,10} \mathrm{h} \mathrm{51,} 12$ h 21 et $13 \mathrm{~h}$ 51, une chronique traite de l'éducation. Le site propose également un accès aux sujets traités récemment. http:// www.radiofrance.fr/chaines/france-info/chroniques/experience/

3 "L'école des savoirs» sur Radio France Internationale (RFI), émission quotidienne de vingt minutes, est diffusée du lundi au vendredi à $20 \mathrm{~h} 40$ heure française. L'émission peut être téléchargée et écoutée sur le site de RFI. Le sommaire des émissions est en ligne chaque semaine. Du lundi au jeudi, des invités et des reportages analysent, souvent en lien avec l'actualité, les questions éducatives en France et à l'étranger. Le vendredi, l'émission devient pratique avec une série de chroniques sur la formation et l'emploi en Afrique et les écoles dans le monde.

4 http://ww.rfi.fr/Fichiers/Magazines/emissions/societe/ecole_des_savoirs_tv.asp

\section{Télévision}

5 France 5 présente le samedi à $10 \mathrm{~h} 10$ (réseau hertzien) et le vendredi à $21 \mathrm{~h} 50$ (câble et satellite), «Cas d'école», une émission de 52 minutes qui aborde l'éducation sous des 
angles divers. Les invités (spécialistes, écrivains, parents et psychiatre) débattent d'un thème choisi. Des reportages et des portraits d'adolescents permettent d'initier les débats sur le plateau. Depuis la rentrée 2004, l'émission se veut davantage interactive: elle donne la parole aux téléspectateurs via le téléphone, les SMS et Internet. http:// www.france5.fr/école

Sur son site, France 2 consacre une rubrique d'informations sur l'éducation alimentée quotidiennement. Il s'agit de dépêches et d'articles sur des questions d'actualité comme les réformes en cours, des rapports à paraître ou des rencontres, colloques, etc. http:// info.france2.fr/education

7 L'émission «Les Maternelles » (durée : $1 \mathrm{~h}$ 30), diffusée du lundi au vendredi à $9 \mathrm{~h}$ sur France 5, propose des chroniques, des dossiers, des débats et des séries documentaires. Une grande discussion de trente-cinq minutes porte sur différents sujets. Un reportage illustre le sujet du jour. La chronique interactive, «les maternelles.com», propose des références d'ouvrages et des adresses pour approfondir le sujet en question. La séquence interactive «c'est avec vous » se fait le porte-parole des téléspectateurs. Des archives thématiques sont accessibles sur le site, parmi lesquelles : l'apprentissage (la lecture, la citoyenneté, l'enseignement du fait religieux, les TICE, les sciences, la peur des maths, l'histoire, etc.), les devoirs (le soutien scolaire, etc.), les problèmes scolaires (l'échec, l'ennui, le redoublement, l'inégalité scolaire, les troubles de l'apprentissage, la violence, etc.), l'intégration des enfants handicapés et des enfants étrangers, les ZEP, la déscolarisation des enfants, les gens du voyage ; la rentrée, la vie scolaire (la mixité, les rythmes scolaires, le grand débat sur l'école, le public et le privé). http://www.france5.fr/ maternelles/

\section{Presse écrite}

Le quotidien national Le Figaro reprend, dans l'une des rubriques de son site, des articles de la version papier portant sur des questions éducatives. Certains se font l'écho des débats actuels, d'autres donnent des informations plus pratiques sur les formations, les cursus, les métiers et les carrières, comme les grandes écoles, les dates des concours, les études à l'étranger, les formations internationales. http://www.lefigaro.fr/education/

Le blog de Libération sur l'éducation

Le quotidien national vient de créer sur son site un blog (contraction de weblog, carnet de bord tenu par un internaute) intitulé "Carnet de correspondance». Ouvert aux analyses d'autres observateurs, il vise à tisser des liens avec ceux qui pensent l'école dans d'autres pays, au moins dans les pays francophones. Ce blog renvoie aussi sur quelques sites. Si les blogs de journalistes sont désormais largement reconnus dans les médias anglo-saxons, l'expérience de Libération est une première dans la presse française en ligne. http:// www.liberation.fr/page.php?Rubrique=BLOGS

11 Mensuel de référence du secteur éducatif, Le Monde de l'éducation, http:// www.lemonde.fr/mde, est une publication mensuelle du quotidien national Le Monde. La nouvelle formule s'articule autour d'un dossier qui traite des grandes questions éducatives. L'éducation, la formation et la culture sont traitées en rapport direct avec l'actualité. Des rubriques et des chroniques complètent les enquêtes de fond. Les sommaires des numéros sont en ligne sur le site du journal Le Monde. 
12 Chaque mois, Le Monde de l'éducation et Côté profs s'associent pour proposer un rendezvous commun articulé autour d'un article, de vidéos et d'un forum de discussion. L'article en question est celui qui compose le dossier mensuel du Monde de l'éducation. En complément à cet article, Côté profs met en ligne des extraits vidéo de programmes diffusés sur France 5, illustrant les sujets évoqués dans le cadre du dossier. Via le forum de discussions, les internautes sont invités à débattre sur le thème du mois. http:// education.france5.fr/mde/W00359/4/118007.cfm

13 Le Monde diplomatique donne accès gratuitement à ses archives sur l'enseignement. À titre d'exemple, voici les titres des articles de sujets traités ces derniers mois : « délits d'initiés sur le marché américain", "misères (et grandeur) de la philosophie ", "la langue arabe ", « la Rolls et la Volkswagen », « les recettes pour une université plus mercantile », «peut-on encore enseigner la Shoah?» http://www.monde-diplomatique.fr/index/ sujet/enseignement.html

INDEX

Index géographique : France

Mots-clés : médias

\section{AUTEUR}

\section{SOPHIE CONDAT}

Documentaliste du centre de ressources documentaires du CIEP 